\title{
ANALYSIS OF VEHICLE REACTION TIME IN ARRIVING THE TOLL GATE
}

\author{
Indra Surianto, Mindar Purwantoro, Marcelinus Armando Santosa and \\ Taufik Roni Sahroni
}

Industrial Engineering Department, BINUS Graduate Program - Master of Industrial Engineering, Bina Nusantara University 11480, Jakarta, Indonesia.

\begin{abstract}
This paper presents the level of road density and the number of vehicles passing on the Jakarta city toll road. This study was conducted at the Jakarta Toll Gate namely Semanggi I, Semanggi II and Halim. Data is obtained from observations when the driver pays the cost of the expressway at the toll gate. This study shows a reaction time for the payment of expressway costs, which are influenced by types of motorized vehicles such as sedans, jeeps, buses, and trucks. The results show that the reaction time of driver when before and after paying, the longest toll road costs is 48 seconds and the shortest is 1 second. Reaction time for the payment of expressway costs could shorten the travel time, with an average reaction time of 6.04 seconds on vehicles. The number of vehicles crossing the toll gate on 24 hours from the three Toll Gates amount 17.256 vehicles. As a result, Most of vehicle traffic contributed by the behavior of driver at the Toll Gate.
\end{abstract}

Key words: Reaction Time, Vehicles, Toll Gate, Driver, Jakarta

Cite this Article: Indra Surianto, Mindar Purwantoro, Marcelinus Armando Santosa and Taufik Roni Sahroni, Analysis of Vehicle Reaction Time in Arriving the Toll Gate. International Journal of Advanced Research in Engineering and Technology, 10(5), 2019, pp. 103-110. http://iaeme.com/Home/issue/IJARET?Volume=10\&Issue $=5$

\section{INTRODUCTION}

The Driver's reaction time, also called "response time", consists of two elements, namely Perception Reaction Time (PRT) and Maneuver Time (MT). PRT is the time it takes for the driver to react and decide on the maneuver that suits the road conditions. For example, a driver will release the foot of the gas pedal and press the brake pedal to avoid hit back [1]. MT, called movement time, is the time needed to complete a maneuver either slowing down or stopping. Many factors influence the driver's reaction time that have not been explored in the literature on driver modeling due to the lack of adequate observation data. Reaction Time is influenced by the level of fatigue, conditions of motivation, boredom, concentration, and human psychological conditions. In addition, it is also influenced by external factors such as lighting, temperature, and vibration. [2].

In addition to the above factors the reaction time is also affected by arousal, age, sex, dominant hand, angle of view, dexterity, fatigue, interference, stimulus, addictive substances, 
environment, and psychological. Arousal is a state of attention which is also influenced by blood pressure [3-5]. Age, reaction time starts from teenagers, adults, and parents. Decreasing reaction time in adults tends to devote his mind to one stimulus and ignore other stimuli [6-10]. Gender, usually men have faster reaction times than women [11-13]. The dominant hand, according to the results of the research, left-handed people react faster than the dominant person with the right hand. Regarding the Viewpoint, the reaction time will be faster if the stimulus is given when the subject looks right at the point of stimulus (direct vision), and can slow down if the stimulus is given around peripheral vision. Agility, when someone does something new, then the reaction time will be longer when compared to someone who has been trained. Fatigue causes the reaction time to slow down. The presence of interference when a stimulus is given can increase reaction time [14]. Warning of the stimulus, the reaction time will be faster if there is a warning sign as a stimulus. Consuming excessive addictive substances can reduce reaction time, as well as environmental factors such as lighting, temperature and psychological factors [15].

There is growing scientific evidence that professional drivers who have psychosocial issues are at high risk of accidents [16-24]. It is known that specifically for professional drivers, work stress is associated with deviant driving behavior [25], which in turn is closely related to road accidents [26].

Driving behavior is at risk associated with individual variables, which are usually handled through road safety training (e.g. certain attitudes, habits, behaviors and performance factors), and certain variables related to the work environment, such as physical and mental fatigue, lack of experience, physical demands or psychological tasks, and work pressure (work characterized by high demands and low control) [27-29]. According to Reason, risky driving behavior can be classified into two main categories: errors and violations. Mistakes are actions that, due to driver shortcomings and errors (e.g. misinterpretation of road conditions, improper handling of vehicles), fail to achieve the desired results. Violations, on the other hand, refer to violations of rules that govern the safety of operations intentionally (e.g. removal of signs - intentional road signs, exceeding the speed limit) [30].

One of the most relevant processes related to driving behavior that is at risk is fatigue [31]. In the specific case of professional drivers, it has been shown that in the context of work, fatigue predicts a greater prevalence of occupational diseases (e.g. cardiovascular and musculoskeletal system disorders), and other health risks that can affect driving safety and health. A recent study found that about $51 \%$ of large vehicle professional drivers felt exhausted during their last trip; however, only $35 \%$ considered that this negatively affected their driving performance [32]. Especially for BRT drivers, it has been concluded that an increase in the level of fatigue contributes to a substantial reduction in their operational safety [33].

Although its influence on driving performance and safety can be very different, tension and job fatigue are often associated in the literature, given the simultaneous prevalence of both phenomena in different high-risk jobs, such as driving professionals. Although fatigue in the workplace does not only occur with workers with work pressure (usually appearing even for those who have active work characterized by high demands and high control, according to the DC model), it has been determined that the demand and control felt at work can explain fatigue index higher or lower among working populations. According to recent studies, continuous exposure to professional driving pressure and incomplete recovery leads to a condition of permanent and accumulated fatigue which becomes evident in the short and medium term in a higher (still reversible) fatigue index. Also in the long term in the physical and mental disorders, including the need to mention fatigue [34-35].

Research found that distracted drivers caused $23 \%$ of adverse traffic accidents and $27 \%$ of fatal traffic accidents at 2004 in Japan [36]. It is widely known that interference affects driver 
reaction time. Experiments are carried out on simulated roads and in other conditions to identify drivers with long reaction times and drivers whose reaction time is strongly influenced by mental workloads while driving on public roads. The reaction time after hearing the bell is measured under five conditions: (1) sitting in a stationary vehicle, (2) carrying out mental calculations in a stationary vehicle, (3) driving on a simulation road, (4) carrying out mental calculations while driving on a simulation road, and (5) driving on public roads. The subjects were 10 drivers each of the three age groups. Each experiment was carried out by this subject under five conditions. The results show that mental calculations increase the average reaction time for each age group. Mental calculations increase differences between age groups and individuals, and increase differences in individual performance of each driver. Mental calculations affect the reaction time of the old driver is very extraordinary. The results also show that experiments on road simulations identify drivers who show long reaction times on public roads [37]. Based on the literature review, there is still a research gap capture the vehicle reaction time particularly in Jakarta toll gate, where the toll gate occupancy is considered very high. Therefore, this study proposes the analysis of vehicle reaction time in arriving the toll gate.

\section{MATERIALS AND METHODS}

The object of research is four-wheeled vehicles or more from each group of different vehicles at the reaction time in front of the toll gate. The group of vehicles in front of the toll gate are cars, sedans, jeeps, pickups, trucks and buses. Each has a different time service in payment transactions. The object to find out service time in payments from groups of vehicles to show the level of the vehicle in front of the toll gate. All vehicles use toll road access to reduce the number of congestion.

To get the data needed for input in micro-simulation for conduct research as follows Recording data in front of the toll gate for a period of 24 hours, data collection is divided into 4 (four) time periods, namely 00.00-06.00, 06.00-12.00, 12.00-18.00, 18.00-24.00. Analysis data from the recording with conditions in various perspectives. Measuring the factual conditions in driving according to the conditions in the four times above (morning, afternoon, evening, and night). Make a comparison of the number of vehicles in all four times in graphical form to determine the difference in Reaction Time between the gates that cross the Vehicles. Make a comparison of the Reaction Time of the vehicle in all four times in the form of a graph to find out the difference in Reaction Time between the gates that cross in making tapping payments. From the results of the research that conducted for the next simulation was made using a Micro Simulation, so that the best concepts can be simulated in regulating traffic ahead of the toll gates in the city of Jakarta.

In this study, the payment queue Reaction Time at three toll gates in the city of Jakarta, namely the Semanggi I toll gate, Semanggi II toll gate and Halim toll gate, are observed. The purpose of which was to capture the pragmatic interaction of vehicles in the payment queue. The cctv video recording data is taken from the office of the Jakarta branch, Tangerang, Cengkareng. The CCTV video records the movements of naturalistic vehicles which are part of the object's study within a 24-hour period, shown in Figure 1, Figure 2 and Figure 3. 


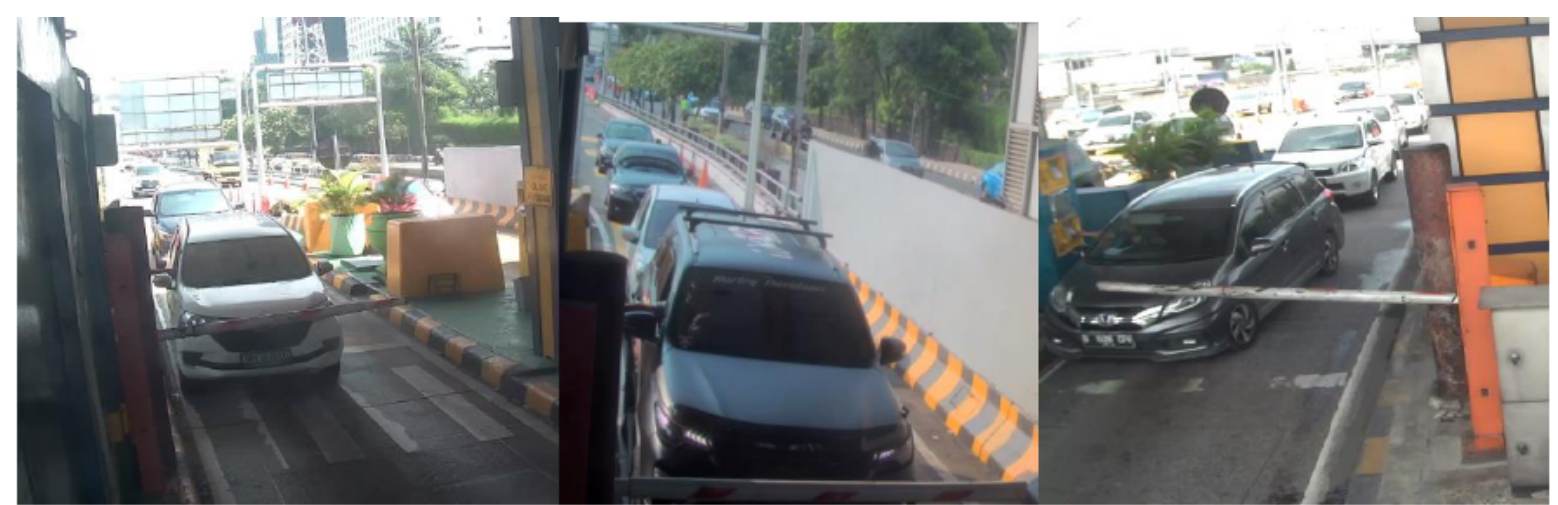

Figure 1 Toll Gate at Semanggi I Figure 2 Toll Gate at Semanggi II Figure 3 Toll Gate at Halim

The observation results of the reaction time at the three toll gates were observed according to four cycles of time, namely: morning, afternoon, evening and night as shown in the following at Table 1.

Table 1 The observation results of the reaction time according to four cycles of time

\begin{tabular}{|c|c|c|c|c|c|c|c|c|c|c|c|c|}
\hline \multirow{2}{*}{ Characteristics } & \multicolumn{3}{|c|}{$00.01-06.00$} & \multicolumn{3}{|c|}{$06.01-12.00$} & \multicolumn{3}{|c|}{$12.01-18.00$} & \multicolumn{3}{|c|}{$18.01-24.00$} \\
\hline & SM-1 & SM-2 & HLM & SM-1 & SM-2 & HLM & SM-1 & SM-2 & Halim & SM-1 & SM-2 & HLM \\
\hline Number of Vehicles & 538 & 684 & 1,153 & 1,002 & 1,125 & 2,528 & 1,783 & 1,788 & 2,112 & 1,610 & 1,587 & 1,346 \\
\hline Average Reaction Time & 6.75 & 5.20 & 7.54 & 6.64 & 5.50 & 6.22 & 6.48 & 4.20 & 6.20 & 6.20 & 5.22 & 6.30 \\
\hline Maximum Reaction Time & 37 & 28 & 46 & 30 & 32 & 41 & 48 & 47 & 35 & 44 & 44 & 33 \\
\hline Minimum Reaction Time & 3 & 1 & 2 & 3 & 1 & 1 & 1 & 1 & 1 & 1 & 1 & 1 \\
\hline Total Reaction Time & 3,955 & 4,288 & 8,623 & 6,655 & 7,568 & 15,965 & 11,551 & 6,221 & 13,509 & 9,986 & 8,000 & 8,771 \\
\hline
\end{tabular}

Note: SM-1 = Semanggi-1 toll gate; SM-2 = Semanggi-2 toll gate; HLM = Halim toll gate

From the four cycles above to show the reaction time pattern between the number of passing traffic and the most dominant time, using bar charts per time cycle in the same time, as shown in the Figure 4, Figure 5, Figure 6 and Figure 7 below.
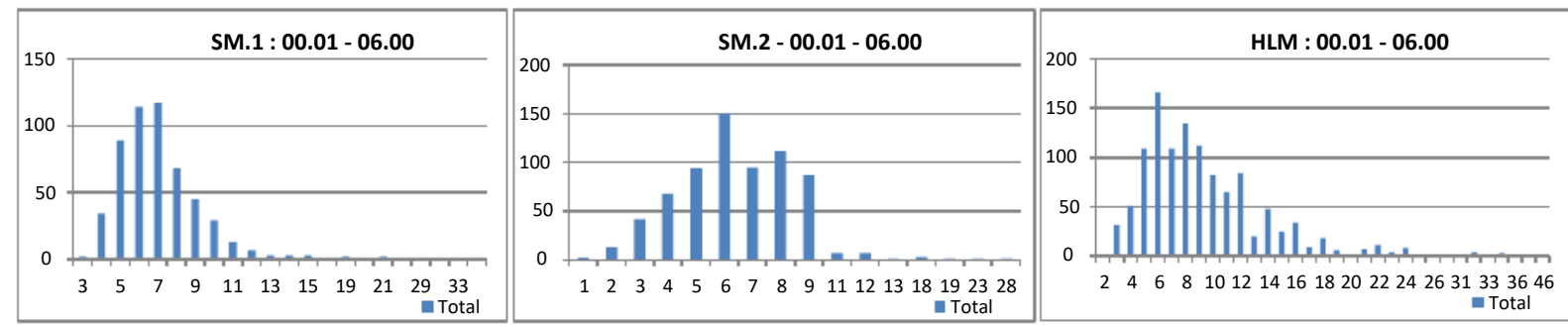

Figure 4 Bar charts for three toll gates at $00.01-06.00$

Note: SM.1 = Semanggi-1 toll gate; $\mathbf{S M . 2}=$ Semanggi-2 toll gate; $\mathbf{H L M}=$ Halim toll gate
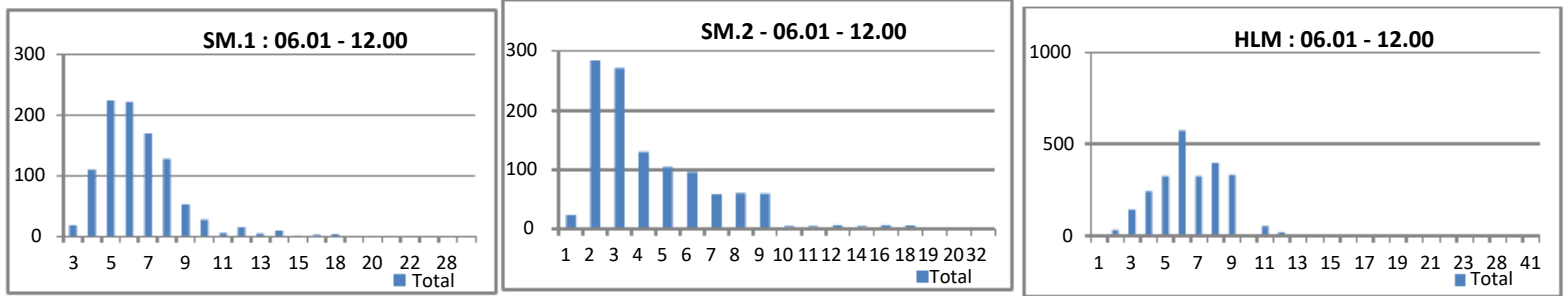

Figure 5 Bar charts for three toll gates at $06.01-12.00$

Note: SM.1 = Semanggi-1 toll gate; SM.2 = Semanggi-2 toll gate $\mathbf{H L M}=$ Halim toll gate 
Analysis of Vehicle Reaction Time in Arriving the Toll Gate
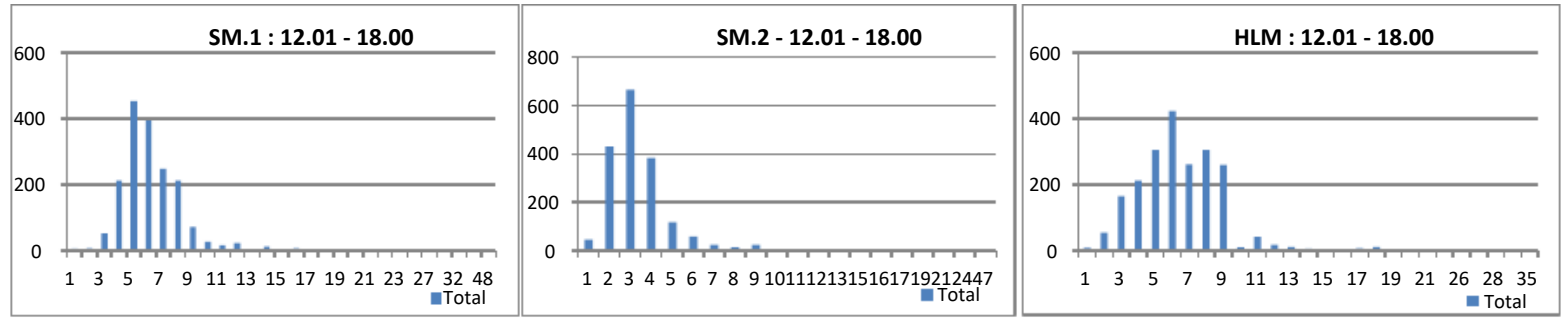

Figure 6 Bar charts for three toll gates at $12.01-18.00$

Note: SM.1 = Semanggi-1 toll gate; SM.2 = Semanggi-2 toll gate $\mathbf{H L M}=$ Halim toll gate
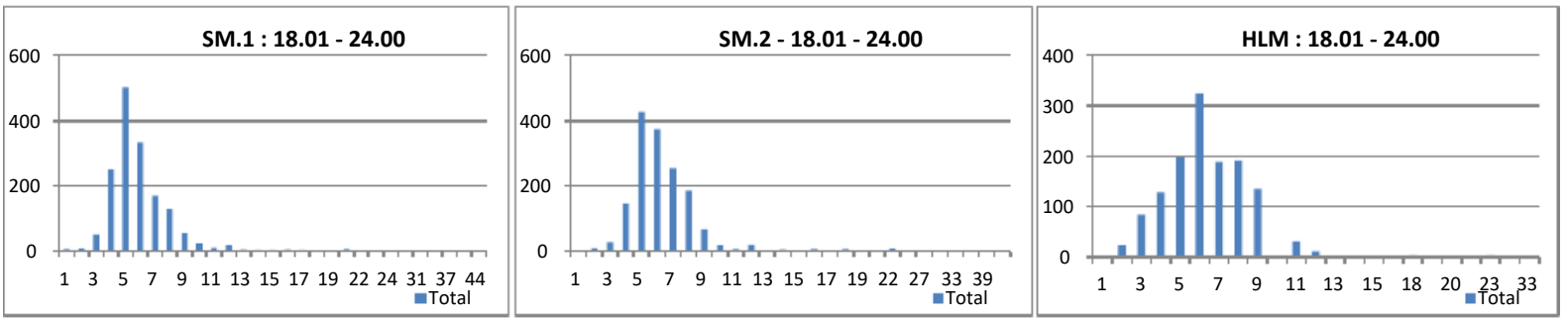

Figure 7 Bar charts for three toll gates at $18.01-24.00$

Note: SM.1 = Semanggi-1 toll gate; SM.2 = Semanggi-2 toll gate; HLM = Halim toll gate

From the above observations there are several different reaction time patterns of driver in the time cycle group of all Toll Gate.

\section{RESULTS}

From the observation of the Reaction Time in the payment process when the vehicle queue is mentioned above, the graph results in 24 hours at the time of payment in front of the Semanggi I Toll Gate, Semanggi II Toll Gate and Halim Toll Gatecan be seen in the Table 2.

Table 2 Total Reaction Time for 24 hours at each Toll Gate observed

\begin{tabular}{|l|c|c|c|}
\hline \multicolumn{1}{|c|}{ Characteristics } & Semanggi 1 & Semanggi 2 & Halim \\
\hline Number of Vehicles & 4,933 & 5,184 & 7,139 \\
\hline Average Reaction Time & 6.52 & 5.03 & 6.57 \\
\hline Maximum Reaction Time & 48 & 47 & 46 \\
\hline Minimum Reaction Time & 1 & 1 & 1 \\
\hline Total Reaction Time & 32,147 & 26,077 & 46,868 \\
\hline
\end{tabular}

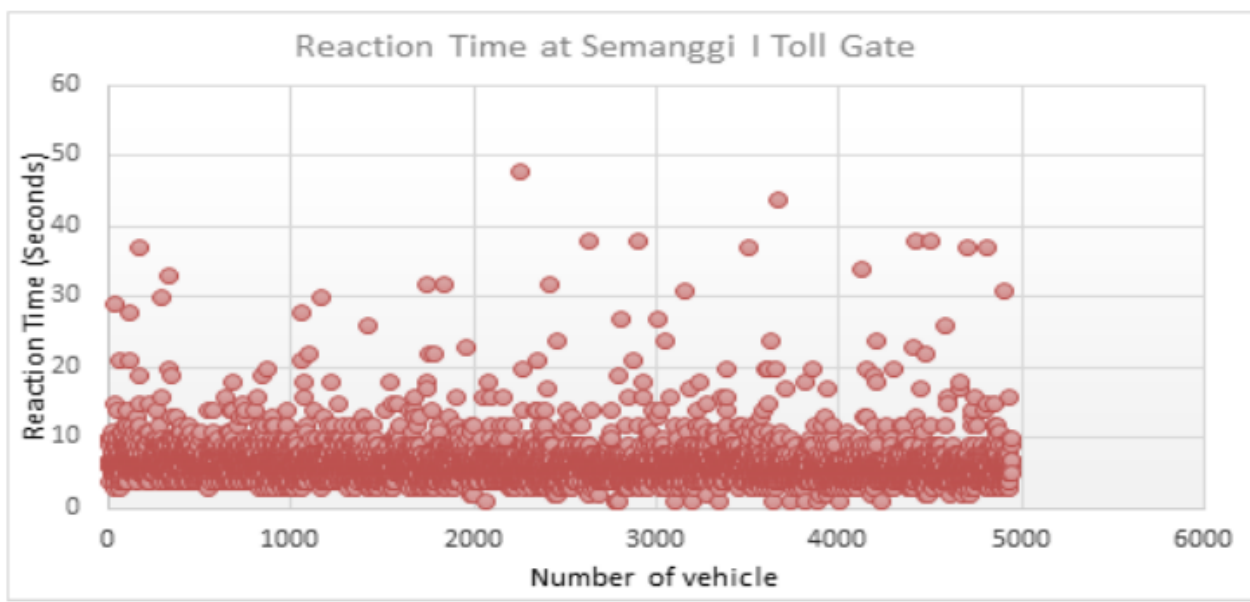

Figure 8 Reaction Time data 24 hours at Semanggi I Toll Gate 
Figure 8 shows the service time cycle in the morning, afternoon, evening and night conditions which shows the density cycle in front of the Semanggi I Toll Gate for 24 hours

Figure 9 shows the service time cycle in the morning, afternoon, evening and night conditions which shows the density cycle in front of the Semanggi II Toll Gate for 24 hours below.

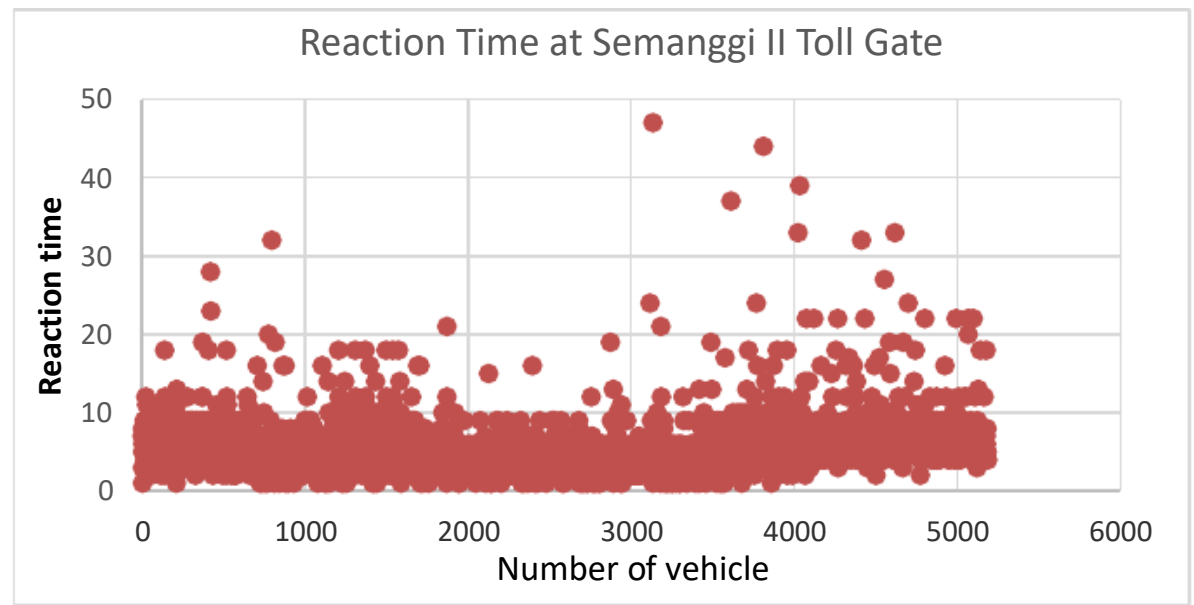

Figure 9 Reaction Time data 24 hour at Semanggi II Toll Gate

Figure 10 shows the service time cycle in the morning, afternoon, evening and night conditions which shows the density cycle in front of Halim Toll Gate for 24 hours below.

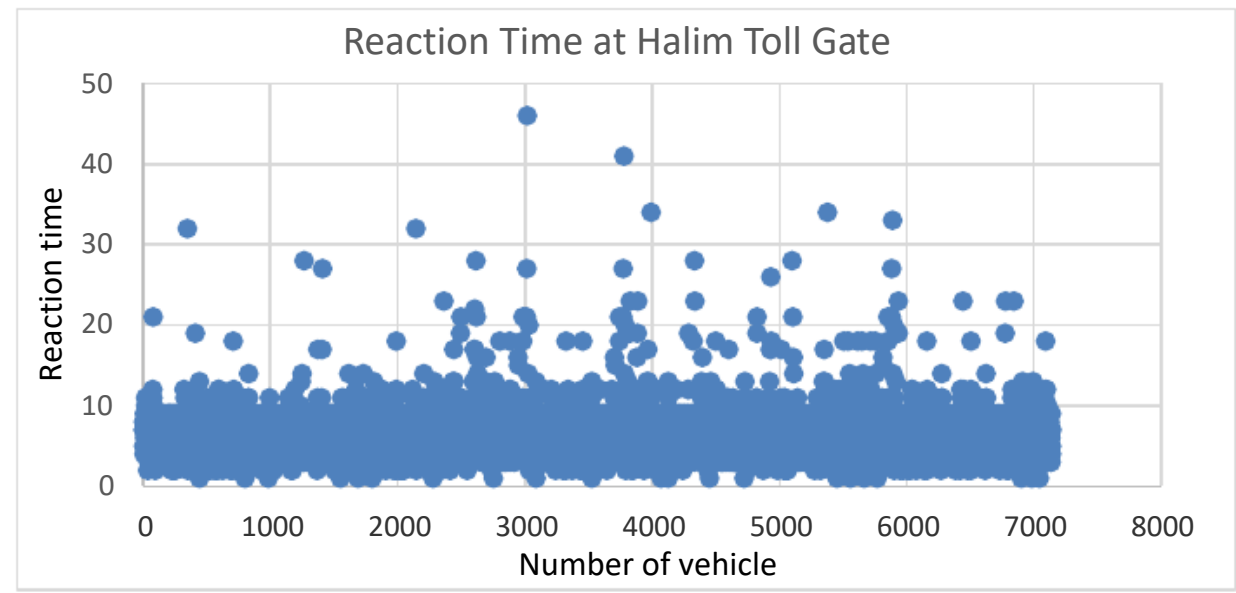

Figure 10 Reaction Time data 24 hour at Halim Toll Gate

\section{CONCLUSION}

The research addresses the number of vehicles crossing the toll gate on 24 hours from the three toll gates amount 17.256 vehicles. Toll gates worked optimally with an average reaction time of 6.04 seconds per vehicle. Based on the results, it is found that the driver reaction differ during payment at the toll gate. The behavior of driver during payment influenced the level of congestion. As a result, most of vehicle traffic contributed by the behavior of driver at the toll gate.

\section{REFERENCES}

[1] Green, M., 2009. Perception-reaction time: is Olson (and sivak) all you need to know? Collision: Int. Compendium Crash Res. 4 (2), 88-93.

[2] Kosinski, Robert J. 2005. A Literature Review of Reaction Time.Clemson University. 
[3] Welford, A. T. 1980. Choice reaction time: Basic concepts. In A. T. Welford (Ed.), Reaction Times. Academic Press, New York, pp. 73-128.

[4] Broadbent, D. E. 1971. Decision and Stress. Academic Press, London.

[5] Freeman, G. L. 1933. The facilitative and inhibitory effects of muscular tension upon performance. American Journal of Psychology 26: 602-608.

[6] Welford, A. T. 1977. Motor performance. In J. E. Birren and K. W. Schaie (Eds), Handbook of the Psychology of Aging. Van Nostrand Reinhold, New York, pp. 450-496.

[7] Jevas, S. and J. H. Yan. 2001. The effect of aging on cognitive function: a preliminary quantitative review. Research Quarterly for Exercise and Sport 72: A-49.

[8] Luchies, C. W., J. Schiffman, L. G. Richards, M. R. Thompson, D. Bazuin, and A. J. DeYoung. 2002. Effects of age, step direction, and reaction condition on the ability to step quickly. The Journals of Gerontology, Series A57(4): M246.

[9] Rose, S. A., J. F. Feldman, J. J. Jankowski, and D. M. Caro. 2002. A longitudinal study of visual expectation and reaction time in the first year of life. Child Development 73(1): 47.

[10] Der, G., and I. J. Deary. 2006. Age and sex differences in reaction time in adulthood: Results from the United Kingdom health and lifestyle survey. Psychology and Aging 21(1): 62-73.

[11] Noble, C. E., B. L. Baker, and T. A. Jones. 1964. Age and sex parameters in psychomotor learning. Perceptual and Motor Skills 19: 935-945.

[12] Adam, J., F. Paas, M. Buekers, I. Wuyts, W. Spijkers and P. Wallmeyer. 1999. Gender differences in choice reaction time: evidence for differential strategies. Ergonomics 42: 327.

[13] Dane, S. and A. Erzurumluoglu. 2003. Sex and handedness differences in eye-hand visual reaction times in handball players. International Journal of Neuroscience 113(7): 923-929.

[14] Miller, C. A. and G. H. Poll. 2009. Response time in adults with a history of language difficulties. Journal ofCommunication Disorders 42(5): 365-379.

[15] Lorist, M. M. and J. Snel. 1997. Caffeine effects on perceptual and motor processes. Electroencephalography and Clinical Neurophysiology 102(5): 401-414.

[16] Đinđić, N., Jovanović, J., Đinđić, B., Jovanović, M., Pešić, M., Jovanović, J.J., 2013. Work stress related lipid disorders and arterial hypertension in professional drivers: a crosssectional study. Vojnosanit. Pregl. 70 (6), 561-568.

[17] Cendales, B., Useche, S.A., Gómez, V., Bocarejo, J.P., 2016. Bus operators' responses to job strain: an experimental test of the job demand-control model. J. Occup. Health Psychol. Adv.

[18] Imran, M.R., Devi, B.S., 2013. Study of changes in cardiovascular and cerebrovascular risk factors due to stress using physiological and biochemical profiles in professional urban bus drivers. Int. J. Recent Trends Sci. Technol. 6, 98-103.

[19] Tse, J.L., Flin, R., Mearns, K., 2006. Bus driver well-being review: 50 years of research. Transp. Res. Part F: Traffic Psychol. Behav. 9 (2), 89-114.

[20] Tse, J.L., Flin, R., Mearns, K., 2007. Facets of job effort in bus driver health: deconstructing effort in the effort-reward imbalance model. J. Occup. Health Psychol. 12 (1), 48-62.

[21] Useche, S., Alonso, F., Cendales, B., Autukevičiūtè, R., Serge, A., 2017a. Burnout, job strain and road accidents in the field of public transportation: the case of city bus drivers. J. Environ. Occup. Sci 5 [Publication in Advance].

[22] Useche, S., Cendales, B., Gómez, V., 2017b. Measuring fatigue and its associations with job stress, health and traffic accidents in professional drivers: the case of BRT operators. EC Neurol. 4 (4), 103-118.

[23] Useche, S., Cendales, B., Alonso, F., Serge, A., 2017c. Comparing job stress, burnout, health and traffic crashes of urban bus and BRT drivers. Am. J. Appl. Psychol. 5 (1), $25-$ 32 . 
[24] Tsai, S.S., Lai, C.H., Shih, T.S., Lin, M.H., Liou, S.H., 2014. High job strain is associated with inflammatory markers of disease in young long-haul bus drivers. J. Occup. Health Psychol. 19 (3), 336.

[25] Kontogiannis, T., 2006. Patterns of driver stress and coping strategies in a Greek sample and their relationship to aberrant behaviors and traffic accidents. Accid. Anal. Prev. 38 (5), 913-924.

[26] Reason, J., Manstead, A., Stradling, S., Baxter, J., Campbell, K., 1990. Errors and violations on the roads: a real distinction? Ergonomics 33 (10-11), 1315-1332.

[27] Arnold, P., Hartley, L., 2001. Policies and practices of transport companies that promote or hinder the management of driver fatigue. Transp. Res. Part F 4 (1), 1-17.

[28] Shappell, S., Wiegmann, D., 2000. The human factors analysis and classification systemHFACS. Office Aviat. Med. Fed. Aviat. Adm. Dep. Transp.

[29] Taylor, A., Dorn, L., 2005. Stress, fatigue, health, and risk of road traffic accidents among professional drivers: the contribution of physical inactivity. Public Health 27, 371-391.

[30] AfWåhlberg, A.E., Dorn, L., Kline, T., 2011. The manchester driver behavior questionnaire as a predictor of road traffic accidents. Theor. Issues Ergon. Sci. 12 (1), 6686.

[31] Gastaldi, M., Rossi, R., Gecchele, G., 2014. Effects of driver task-related fatigue on driving performance. Procedia-Soc. Behav. Sci. 111 (955).

[32] Amundsen, A., Sagberg, F., 2003. Hours of Reaction Regulations and the Risk of Fatigueand Sleep-related Road Accidents: A Literature Review. TransportøkonomiskInstitutt (TØI), Oslo.

[33] SUR, 2011. Fortalecimiento De La Seguridad Vial En El TransporteUrbano: El Caso De Bogotá. Grupo de Sostenibilidad Urbana y Regional. Universidad de Los Andes, Bogotá.

[34] Desmond, P., Matthews, G., 2009. Individual differences in stress and fatigue in two field studies of driving. Transp. Res. Part F 12 (4), 265-276.

[35] de Lange, A.H., Kompier, M.A., Taris, T.W., Geurts, S.A., Beckers, D.G., Houtman, I.L., Bongers, P.M., 2009. A hard day's night: a longitudinal study on the relationships among job demands and job control, sleep quality and fatigue. J. Sleep Res. 183, 374-383.

[36] National Police Agency, Japan, 2005. Statistics 2004 Road Accidents Japan.

[37] Hiroshi Makishita and KatsuyaMatsunaga, (2008). Differences of drivers reaction times according to age and mental workload. Accident Analysis and Prevention 40: 567-575.

[38] Nandagopal N, Jerry Prashant D and Giridharan A (2017), A New Approach for Vehicle Maneuverability Using Steer by Touch Technology, International Journal of Mechanical Engineering and Technology 8(9), 2017, pp. 150-156.

[39] Georg Georgovich Ter-Mkrtichian, Alexey Stanislavovich Terenchenko (2018), Kirill Evgenievich Karpukhin, Alternative Ways for Vehicle Ice Development, International Journal of Mechanical Engineering and Technology, 9(5), 2018, pp. 966-973.

[40] E.T. Mukti, A. Sjafruddin, A. Kusumawati and S. S. Wibowo (2017), Analysis Model of Vehicle Operation Speed Prediction of Light Vehicle On 2/2 UD Interurban Road in Indonesia, International Journal of Civil Engineering and Technology, 8(10), 2017, pp. $735-742$. 